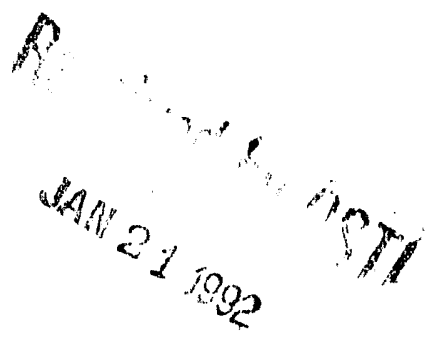

J. C. McDonaild

K. L. Swinth

J. M. Selby

October 1991

Presented at the

Hanford Life Sciences Symposium

october 29 - November 1, 1991

Richland, Washington

Work supported by

the U.S. Department of Energy

under Contract DE-ACO6-76RLO 1830

Pacific Northwest Laboratory

Richland, Washington 99352

\title{
DISCLAIMER
}

This report was prepared as an account of work sponsored by an agency of the United States Government. Neither the United States Gnvernment nor any agency thereof, nor any of their employees, makes any warranty, express or implied, or assumes any legal liability or responsibility for the accuracy, completeness, or usefulness of any information, apparatus, product, or process disclosed, or represents that its use would not infringe privately owned rights. Reference herein to any specific commerciai product, process, or service by trade name, trademark, manufacturer, or otherwise does not necessarily constitute or imply its endorsement, recommendation, or favoring by the United States Government or any agency thereof. The views and opinions of authors expressed herein do not necessarily state or reflect those of the

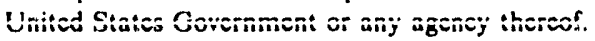


RuLSA-19460

\section{ACCREDITATION OF IONIZING RADIATION PROTECTION PROGRAMS}




\begin{abstract}
ACCREDITATION OF IONIZING RADIATION PROTECTION PROGRAMS* Joseph C. McDonald, Kenneth L. Swinth and Jack M. Selby Pacific Northwest Laboratory Richland, Washington 99352
\end{abstract}

* (Work Supported by the U.S. Department of Energy under Contract DE-ACO676RLO 1830) 
Abstract

Accreditation is a process for evaluating the performance of organizations that provide essential information. The first element in an accreditation program is a written standard that delineates the criteria for judging acceptable performance from such organizations. It is also necessary to have an officially recognized group to administer the program and grant accreditation. Finilly, it is necessary to designate a laboratory that will evaluate performarce, and to appoint site assessors to audit the organizations seeking accreditation.

There are over one million workers in the United States who have the potential to be exposed to ionizing radiation. Therefore, it is necessary to determine accurately the quantity of radiation to which they may have been exposed. This quantity is measured by personnel dosimeters that are carried by individuals requiring radiation monitoring.

Accreditation of the organizations which evaluate this quantity provides official recognition of the competence of these organizations. Accreditation programs in the field of ionizing radiation protection have been in operation for a number of years, and their experience has demonstrated that such programs can help to improve performance. The National Voluntary Laboratory Accreditation Program (NVI_AP) and the Department of Energy Laboratory Accreditation Program (DOELAP) accredit nearly all of the organizations that offer personnel radiation dosimetry services in the United States. 


\section{Introduction}

The risk associated with exposure to ionizing radiation can be quantified by measuring radiation dose, or dose equivalent. Absorbed dose is the quantity of radiation energy deposited per unit mass of a substance. The dose equivalent is the product of the physical absorbed dose deposited in the human body and a quality factor that reflects the relative biological effect of the particular type of radiation. Radiation protection programs us? electronic instruments to measure dose equivalent rates in the workplace, along with personnel dosimeters to measure the dose equivalent delivered to individual workers.

The accuracy and uniformity of the results obtained from personnel dosimeters have been studied, $(1-3)$ and these studies recommended the formation of a national program to accredit the processors of personnel dosimeters. The federal agencies concerned with the regulation of ionizing radiation proposed new rules to cover the accreditation of persorinel dosimetry.

The Nuclear Regulatory Commission (NRC) sponsored a pilot accreditation program (4) to test the proficiency of personnel dosimetry processors. The testing was based on an American National Standards Institute (ANSI) standard(5) entitled, "Proficiency Testing of Personnel Dosimetry Systems". After the results of this pilot study were evaluated, a fult-scale program was initiated. It is administered by the National Institute of Standards and Technology (NIST) as part of the National Voluntary Laboratory Accreditation Program (NVLAP). NRC requires its licensees to obtain dosimetry services from processors that participate in and gain accreditation from the NVLAP personnel dosimetry program. (6) 
The Department of Energy (DOE) also developed a personnel dosimetry accreditation program for the specialized needs of its facilities. The Department of Energy Laboratory Accreditation Program (DOELAP) is based on a DOE performance testing standard, (7) and participation by DOE dosimetry processors is required by a DOE order. (8)

\section{Accreditation Methodology}

Once consensus standards have been established that describe methods for evaluating performance in a specified area, it is necessary to implement the accreditation program. This implementation process includes: proficiency testing according to the methods set out in the standard, onsite assessments of organizations seeking accreditation and committees to decide on, and subsequently grant, accreditation to organizations that have successfully met al1 of the requirements contained in the standard (or other documents defining the program).

Proficiency testing for the personnel dosimetry accreditation programs requires evaluation of the accuracy and precision of a series of test measurements made using personnel dosimeters that are submitted to a performance testing laboratory by the organization seeking accreditation. The measurements are repeated using different types of radiations that are similar to the types expected to be measured by the dosimeters under actual working conditions.

In order to have a quantititive measure of performance, it is necessary to define a performance criterion and to define a method for comparing performance to this criterion. The two variables that are considered to be rete- 
vant to the performance of personnel dosimeters are accuracy and precision. Accuracy is defined as the difference between the dose equivalent value measured by a dosimeter and the actual dose equivalent delivered by the performance testing laboratory. This quantity is often expressed as a fraction of the delivered dose equivalent and, in this case, is referred to as the bias, B. The standard deviation, $S$, is determined by evaluating the variance in the value of the dose equivalent measured by a group of dosimeters exposed to the same quantity of radiation.

When evaluating a measurement system, it is possible to have a series of measurements that is, on average, quite accurate. This would be reflected by a small value of the bias. However, this same set of measurements may have a large standard deviation indicating a lack of reproducibility. On the other hand, a series of measurements might be very reproducible, but might have a large bias, indicating poor accuracy. Neither situation is acceptable, therefore the personnel dosimetry testing programs use a combination of bias plus standard deviation that is compared to the performance criterion, $L$. This is expressed in the inequality below.

$$
B+S \leq L
$$

The absollite value of the bias is used because it is equaliy likely that the bias can be either positive or negative. The values for the performance criterion are given in the consensus standards and are based on recommendations of national and international standards documents. (9). In the case of the personnel dosimetry accreditation programs, values ranging between 30 and $50 \%$ are used, depending upon the radiation and the testing category. 
A group of technical experts is appointed to make onsite assessments of the organizations seeking accreditation. These assessors visit the organizations and audit the key elements of the dosimetry processing operation. These elements include: the quality assurance system, laboratory record books, Taboratory procedures, equipment, dosimeters, calibration procedures, data reports and personnel. The onsite assessors report on their findings to the program administrators. Any serious deficiencies identified require a written plan for resolution. When an organization has successfully completed the performance tests and the technical evaluation by the onsite assessors, accreditation is granted for a specified time period (usually two years). After this time has expired, the organization must apply for re-accreditation.

\section{Current Status of Dosimetry Accreditation Programs}

The DOELAP and NVLAP programs have been in operation since 1984. From this time to the present, many performance tests and assessments have taken place. Initially, the performance of some processors was poor but as improvements were made in dosimetry systems performance improved. The average values of the performance are presently well below the performance criteria limits. Typical values in the NVLAP program range from 0.14 to 0.19 , compared to the performance criteria limits which are between 0.30 and $0.50 .(10)$ Performance in the DOELAP program is comparable.

Both programs are considering revisions, updates and expansions into new areas of accreditation. Extremity dosimeter testing and accreditation is under development and should commence this year. (11) A bioassay testing program is being developed to accredit facilities that perform in-vivo and 
in-vitro bioassay measurements for the purpose of determining the dose delivered to individuals from the intake of radionuclides. In addition, methods are being developed to accredit internal dosimetry programs. (12)

\section{Summary}

Studies of the performance of personnel dosimetry programs in the U.S. indicated that there was a need to upgrade the performance of these programs and that a national effort should be undertaken to achieve this goal. Two programs were developed in response to this recommendation, and they were DOELAP and NVLAP. These programs have been in operation since 1984 and they have helfed to improve the performance of personnel dosimetry processors. The programs are now investigating new areas that would benefit from the accreditation process, including: extremity dosimetry, bioassay and internal dosimetry programs.

The techniques used to by the DOELAP and NVLAP programs can be adapted for use in other fields. In any other area where critical information is generated by a measurement process, the accreditation process can be used to evaluate and document the performance capability of the organizations that provide such information. This approach is particularly useful in areas where the information relates to the health and safety of indiv' 'wals. 


\section{References}

1. Unruh, C.M., Larson, H.V., Beetle, T.M. and Keene, A.R. The Establishment and Utilization of Film Dosimeter Performance Criteria. BNWL-542, September 1967, Battelle Pacific Northwest Laboratory, Richland, Washington (1967).

2. Conference of Radiation Control Program Directors, Summary Report of Workshop No. 3, Personnel Dosimetry Evaluation and Control. Proceedings of the 5th Annual National Conference on Radiation Control, DHEW Publication (FDA) 74-8008, U.S. Government Printing Office, Washington, D.C. (1973).

3. Weiss, B.H. Personal Monitoring Performance Standards, in Measurements for the Safe Use of Radiation. NBS Special Pulbication 456, November 1976, National Institute of Standards and Technology, Gaithersburg, Maryland (1976).

4. Plato, P. and Hudson, G. Performance Testing of Personnel Dosimetry Services, NUREG/CR-1064, January 1980, U.S. Nuclear Regulatory Commission, Washington, D.C. (1980).

5. American National Standards Institute (ANSI), American National Standard, Criteria for Testing Personnel Dosimetry Performance, ANSI N13.11-1983, (1983).

6. United States Federal Register, Standards for Protection Against Radiation, 10 CFR Part 20, U.S. Government Printing Office, Washington, D.C. (1991).

7. United States Department of Energy Standard for the Performance Testing of Personnel Dosimetry Systems, DOE/EH-0027, U.S. Department of Energy, Washington, D.C. (1986).

8. United States Department of Energy Laboratory Accreditation Program for Personnel Dosimetry, DOE Order 5480.15 , U.S. Department of Energy, Washington, D.C. (1987).

9. International Commission on Radiological Protection (ICRF). General Principles of Monitoring for Radiation Protection of Workers, ICRP Publication 35, Pergamon Press, Oxford, United Kingdom (1982).

10. Gladhi11, R.L., NVLAP Program Handbook Personnel Radiation Dosimetry, Requirements for Accreditation, NISTIR 89-4125, July 1989, National Institute of Standards and Technology, Washington, D.C. (1989).

11. Harty, R., Reece, W.D., Hooker, C.D. and McDonald, J.C. Performance Testing of Extremity Dosimeters Against a Draft Standard. PNL-6267, Pacific Northwest Laboratory, Richland, Washington (1990).

12. Fenrick, H.W. and MacLellan, J.A. Recommended Procedures for Performance Testing of Radiobioassay Laboratories. PNL-6067, Pacific Northwest Laboratory, Richland, Washington (1988). 

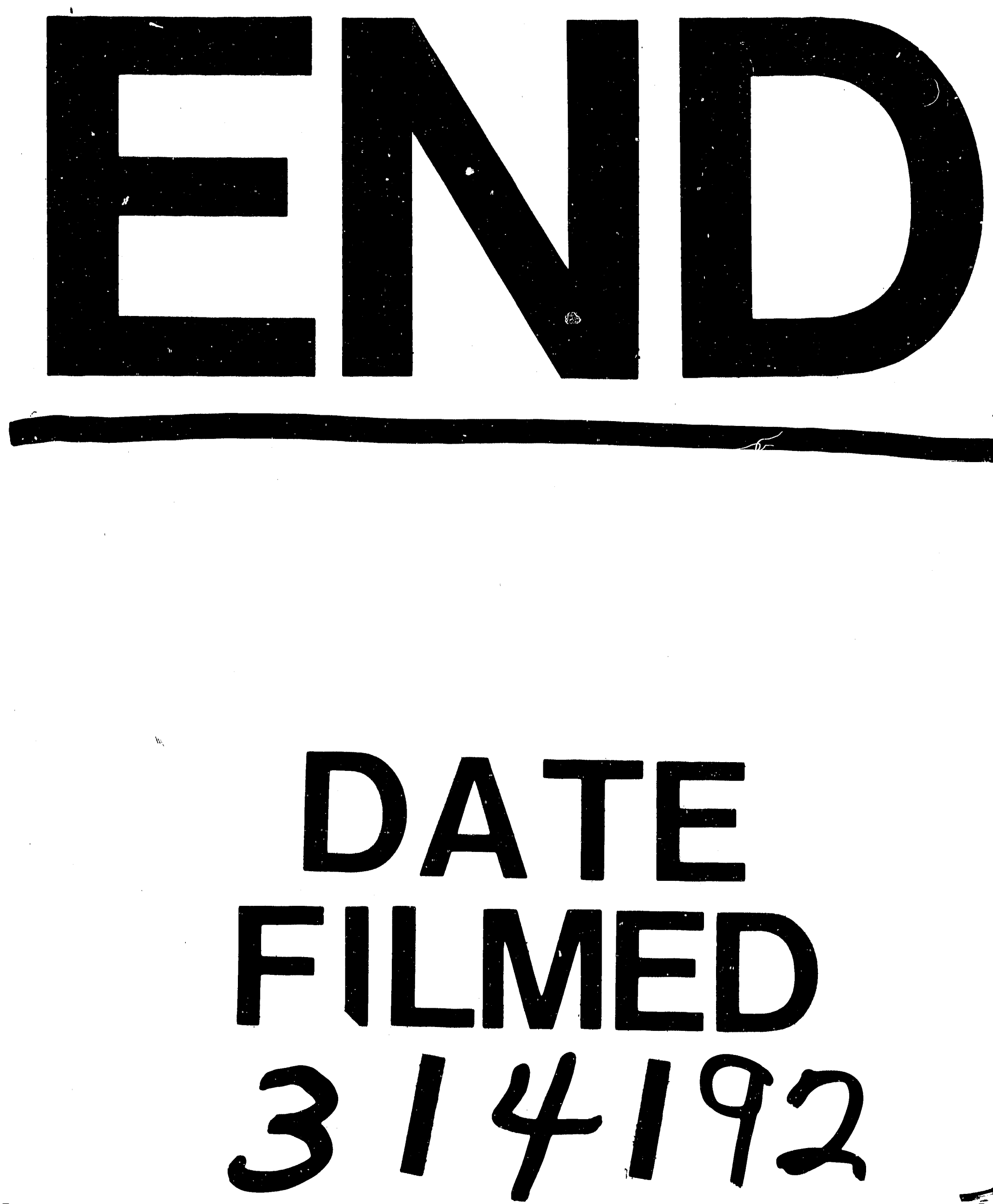

$-$ 


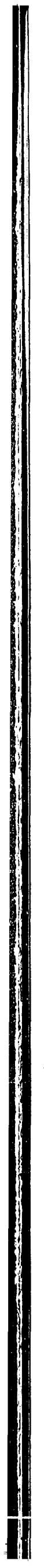

